\title{
Rancang Bangun Jig Rotary Table Menggunakan Motor Servo HG-KR43B pada Mesin Spot Welding
}

\author{
1Suhartinah, ${ }^{2}$ Muhammad Hidayat \& ${ }^{3}$ Ardi Winata \\ Program Studi Teknik Produksi \& Proses Manufaktur, Konsentrasi mekatronika \\ Politeknik Manufaktur Astra \\ JI. Gaya Motor Raya No.8, Sunter II, Jakarta 14330, Jakarta
}

\section{zahrasaina@gmail.com}

\begin{abstract}
Abstrak
Semakin ketatnya persaingan antara car maker membuat masing-masing car maker mengeluarkan inovasi mobil dengan model baru andalannya, baik mobil city car, pick up, sedan, dan lain-lain. Salah satu komponen terpenting dari mobil adalah air conditioner (AC) yang didalamnya terdapat condenser. Inovasi model baru mobil ini mempengaruhi permintaan perubahan model condenser dari sebelumnya. Perbedaan itu terletak pada posisi al-bracket yang berada pada posisi modulator dan tank header yang dilakukan dengan proses welding, sedangkan condenser model lain yang sudah diproduksi memiliki posisi al-bracket pada side plate yang dilakukan dengan proses caulking. Tujuan penulisan ini merancang dan membuat mesin spot welding baru yang dapat melakukan pergerakan rotary pada jig table-nya dengan menggunakan motor servo Mitsubishi HG-KR43B. Proses welding tersebut membutuhkan 3 buah jig clamping untuk setiap proses antara tank header, al-bracket, dan modulator. Hasil dari penelitian ini jig rotary table pada mesin spot welding dapat bergerak sesuai dengan sudut welding yang dibutuhkan yaitu $17^{\circ}$ sehingga dapat melakukan proses welding untuk memenuhi spesifikasi condenser baru.

Kata Kunci: condenser, jig rotary table, spot welding, motor servo
\end{abstract}

\section{Pendahuluan}

Condenser merupakan salah satu dari komponen car AC yang berfungsi untuk membuang suhu panas yang bertekanan tinggi hasil dari pemampatan gas refrigerant dari kompresor sehingga merubah refrigerant tersebut dari gas menjadi cair. Fungsi produk condenser tersebut dapat berjalan dengan adanya kelengkapan dari komponen penyusun utama, yang meliputi fin cooling, main tube, plate header,side plate, tank header, modulator, separator, tube connector in \& out. Proses pembuatan condenser dibagi menjadi 5 bagian , yaitu Core Assembling, Part Assembling, Brazing, Leak Test dan Final Assembling. Mengikuti perkembangan teknologi yang semakin pesat mempengaruhi car maker untuk terus berinovasi membuat mobil dengan model baru andalanya, baik mobil city car, pick up, sedan, dan sebagainya. Salah satu car maker di indonesia mengeluarkan mobil pick up baru. Mobil pick up tersebut akan menggunakan condenser baru dari sebelumnya. Permintaan model baru untuk produk condenser ini dinamakan model XY. Condenser XY memiliki desain yang berbeda dengan produk condenser lain yang sudah diproduksi sebelumnya. Perbedaan itu terletak pada posisi albracket yang berada pada posisi modulator dan tank header yang dipasang dengan proses welding, sedangkan condenser model lain yang sudah diproduksi memiliki posisi al-bracket pada side plate yang dilakukan dengan proses caulking. Adanya perbedaan tersebut, maka membutuhkan proses baru yaitu welding. Untuk memenuhi spesifikasi dari model condenser $X Y$ itu membutuhkan pembuatan program dan pembuatan mekanisme mesin welding. Jig untuk caulking yang sudah ada tidak memungkinkan untuk melakukan proses assembling antara albracket dengan modulator dan tank header. Untuk memenuhi spesifikasi dari condenser model baru dibutuhkan mesin welding yang dapat melakukan tiga kali proses welding untuk menggabungkan yaitu:

1. Modulator dengan tank header.

2. Al - Bracket dengan modulator.

3. Al-Bracket dengan tank header.

Berdasarkan permasalahan tersebut, maka dilakukan pengamatan, analisa dan perancangan untuk menangani hal tersebut. Maka berdasarkan analisa dan pengamatan dirancanglah pembuatan mesin spot welding baru dengan desain dan mekanisme yang sesuai dengan spesifikasi dari condenser XY.

\section{Diskusi}

\subsection{Pengenalan Produk}

Condenser yang berfungsi untuk membuang suhu panas yang bertekanan tinggi hasil dari pemampatan gas refrigerant dari kompresor sehingga dapat merubah refrigerant tersebut dari gas menjadi cair. Fungsi produk condenser 
tersebut dapat berjalan dengan adanya kelengkapan dari komponen penyusun utama, yang meliputi fin cooling, main tube, plate header,side plate, tank header, modulator, separator, tube connector in \& out. Berikut bentuk fisik dari condenser model XY.

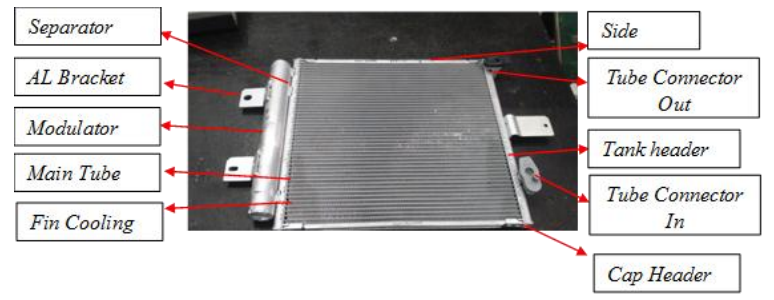

Gambar 1 condenser model XY

Berdasarkan gambar 1 berikut penjelasan dari masing-masing fungsi penyusun condenser :

\section{Fin Cooling}

Fin cooling adalah bagian dari condenser yang terbuat dari alumunium strip yang dibentuk seperti gelombang yang didalamnya terdapat sirip yang dibentuk menggunakan mesin fin forming. Fin cooling ini berfungsi untuk membantu pelepasan kalor pada saat gas refrigerant masuk ke condenser dan melewati main tube.

\section{Main Tube}

Main tube merupakan bagian condenser yang berfungsi sebagai jalur sirkulasi gas refrigerant yang dimana di dalamnya terdapat fin yang berfungsi untuk menjaga main tube agar tidak pecah saat diberikan tekanan gas yang tinggi.

\section{Plate Header}

Bagian condenser yang berfungsi sebagai tempat fitting main tube dan pada proses berikutnya akan dipasang dengan tank header dengan cara crimping.

\section{Tank header}

Bagian condenser yang berfungsi untuk tempat fitting modulator dan tube connector in dan out yang dimana proses pemasangannya dengan cara caulking.

\section{Side Plate}

Bagian condenser yang berada pada sisi paling luar daripada deretan tube dan fin yang berfungsi untuk melindungi fin dari benturan dan memperkokoh condenser.

\section{Modulator}

Bagian condenser yang berfungsi sebagai tempat penyaringan uap air dan kotoran.

7. Separator
Bagian condenser yang berfungsi untuk mengarahkan jalur sirkulasi gas refrigerant.

\section{Tube Connector IN}

Bagian condenser yang menjadi jalur masuknya gas refrigerant saat diberikan tekanan dari kompresor.

\section{Tube Connector Out}

Bagian condenser yang menjadi jalur keluarnya gas refrigerant saat telah mengalami proses kondensasi di condenser dan dilanjutkan ke proses selanjutnya.

\subsection{Permasalahan Proses Al-Bracket Assembling untuk Model XY}

Perbedaan posisi bracket untuk model condenser $\mathrm{XY}$ yaitu berada pada modulator dan tank header yang berbeda dengan model condenser lainya, hal itu membuat tidak mungkinnya proses al-bracket assembling dapat dilakukan dengan jig bracket caulking. Berikut gambar 2 menunjukan perbedaan posisi al-bracket.

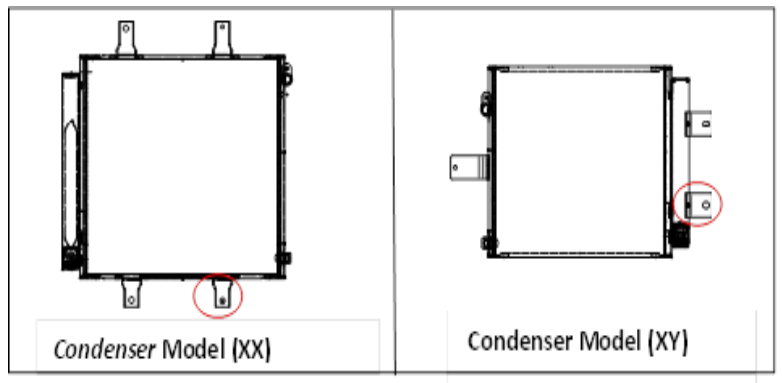

Gambar 2 Perbedaan posisi al-bracket condenser model $X X$ dengan $X Y$

\subsection{Solusi}

Berdasarkan permasalahan yang dijelaskan pada gambar 2 maka ditemukanlah sebuah solusi yaitu dengan membuat mesin spot welding yang dapat melakukan proses welding secara otomatis dan dapat melakukan pergerakan rotary menggunakan motor servo Mitsubishi HG-KR43B yang sudah terintegrasi encoder dan yang nantinya akan dikontrol pergerakanya menggunakan PLC agar dapat memenuhi sudut welding yang disesuaikan dengan desain dari condenser. Gambar 3 dibawah ini menunjukan posisi dan jumah titik welding albraket pada model condenser baru. 
Seminar Nasional Instrumentasi, Kontrol dan Otomasi (SNIKO) 2018 Bandung, Indonesia, 10-11 Desember 2018

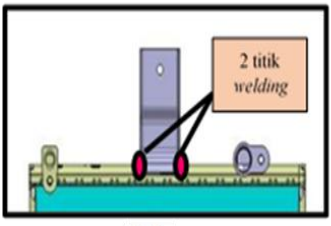

(a)

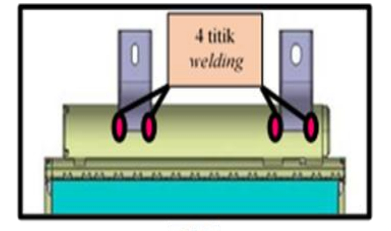

(b)
Gambar 3 Posisi dan jumlah titik welding untuk model $\mathrm{XY}$

(a) Al-bracket dengan Tank header, (b) Al-bracket dengan Modulator

Berdasarkan desain dari model XY didapatkan bahwa membutuhkan 4 titik welding untuk proses assembling al-bracket ke modulator dan 2 titik welding untuk proses assembling al-bracket ke tank header.

\subsection{Perancangan}

\subsubsection{Perancangan Desain Mekanik Mesin Spot Welding}

Penggunaan motor servo pada jig rotary table bertujuan untuk menggerakan jig secara rotary agar sudut yang dibutuhkan pada saat proses welding dapat diatur sehingga spesifikasi yang dibutuhkan untuk condenser model XY dapat terpenuhi. Berikut ini adalah rancangan desain mesin spot welding.

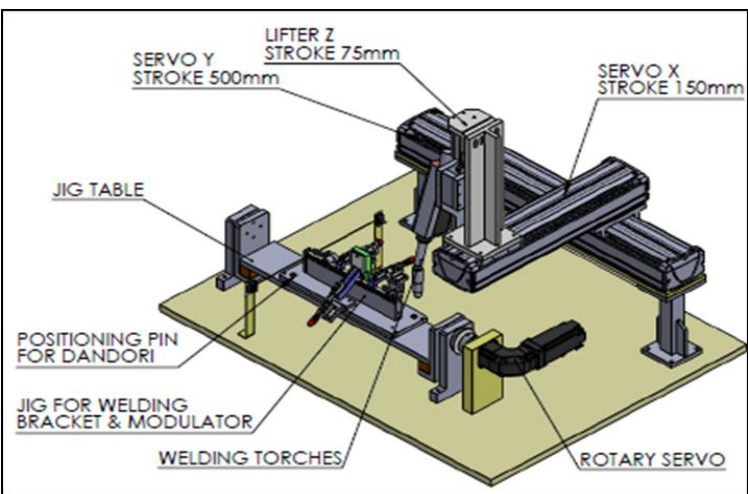

Gambar 4 Desain mekanik mesin spot welding

Mekanisme pergerakannya yaitu, ketika motor servo berputar, putaran motor servo akan memutar coupling yang tersambung dengan jig table yang kemudian jig table pun akan berputar mengikuti pergerakan motor servo.

\subsubsection{Perancangan Jig Rotary table}

Perancangan jig rotary table sebagai base untuk tempat menyimpan jig clamping disesuaikan dengan mesin spot welding itu sendiri. Berikut gambar perancangan dari jig rotary table ditunjukan pada gambar 5 di bawah ini.

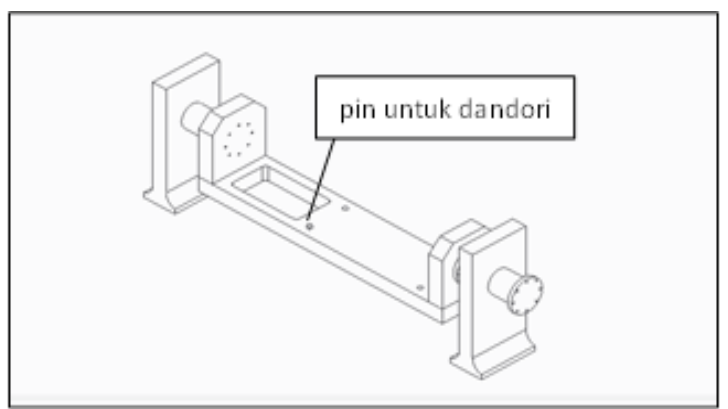

Gambar 5 Perancangan jig rotary table

Pada rotary table dibuat sebuah pin yang berfungsi untuk memudahkan operator saat melakukan pergantian jig clamping dan proses welding selalu dengan posisi yang sama. Selanjutnya yaitu perancangan jig clamping, jig ini menyesuaikan dengan bentuk part yang nantinya akan diproses. Proses untuk memenuhi spesifikasi model $X Y$ membutuhkan 3 proses yaitu:

a) Proses welding modulator dengan tank header

b) Proses welding modulator dengan al-bracket

c) Proses welding tank header dengan al-bracket

Berdasarkan proses yang dibutuhkan maka dibuatlah perancangan jig untuk setiap prosesnya. Berikut gambar perancangan jig clamping akan ditunjukan pada Gambar 6.

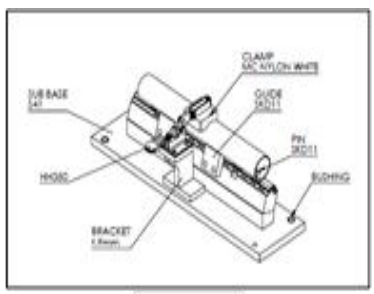

(a)

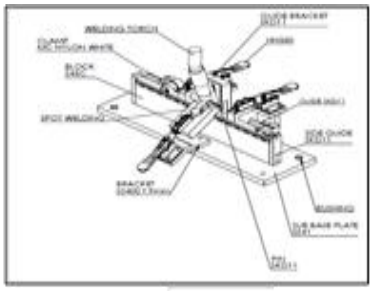

(b)

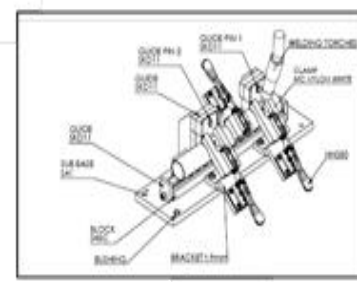

(c) 


\subsubsection{Perancangan Flow Chart Mesin Spot Welding}

Berdasarkan perbedaan proses assembling albracket antara model condenser XX dan XY yaitu menggunakan proses welding yang membutuhkan pergantian jig untuk setiap prosesnya membuat flow chart proses pada mesin spot welding yang baru seperti gambar 7 berikut:
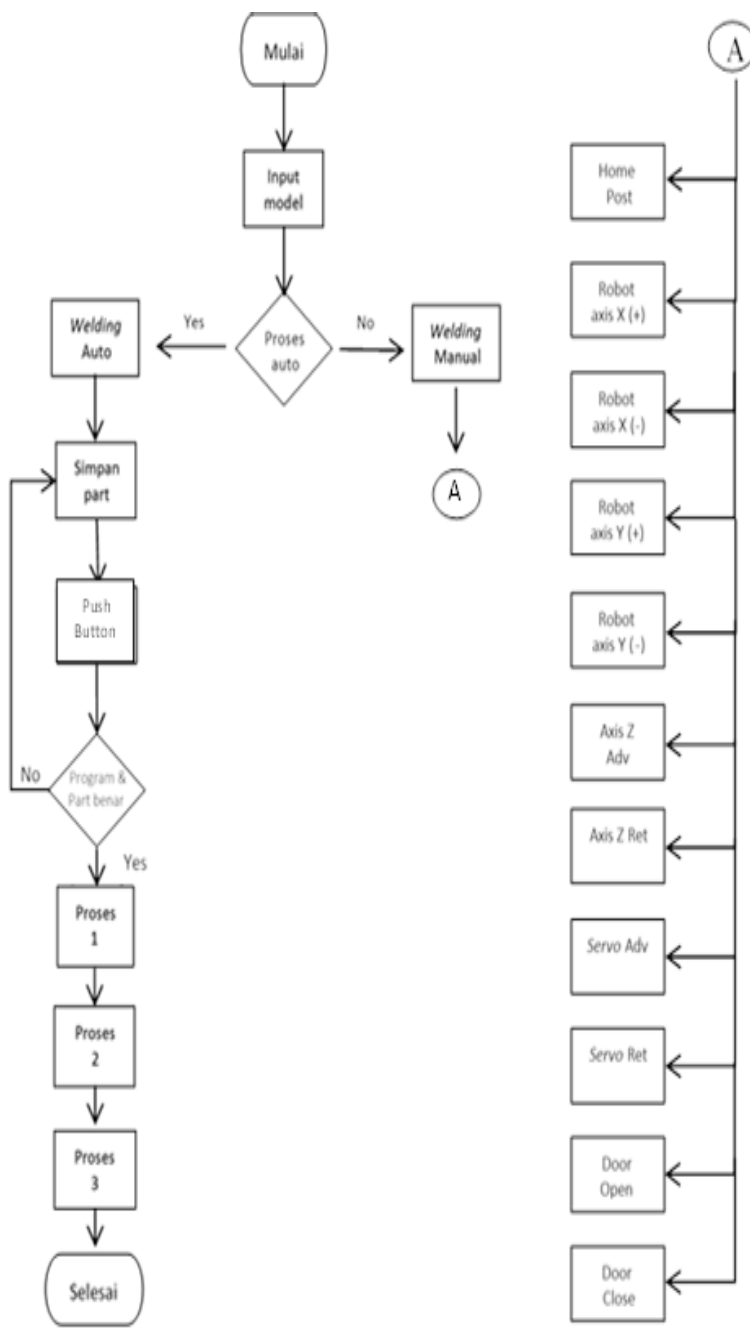

\section{Gambar 7 Preancangan flowchart mesin spot welding}

Berdasarkan Gambar 7, urutan flow chart proses spot welding yang baru yaitu dimulai dari input model condenser yang akan diproses, kemudian pilih manual atau otomatis dengan memutar selector switch, jika memilih otomatis maka simpan part pada jig, jika jig dan program telah sesuai maka proses selanjutnya dapat dilakukan yaitu dengan menggerakan nagara switch maka pintu cover akan menutup dan proses welding pun berlangsung, setelah welding selesai lalu pintu cover pun membuka otomatis dan lakukan proses berikutnya dengan urutan yang sama.

\section{Pembuatan Mekanik}

Sesuai konsep desain yang digambarkan pada bagian perancangan, berikut adalah pembuatan mekanik jig dan rotary table mesin untuk ketiga proses welding :

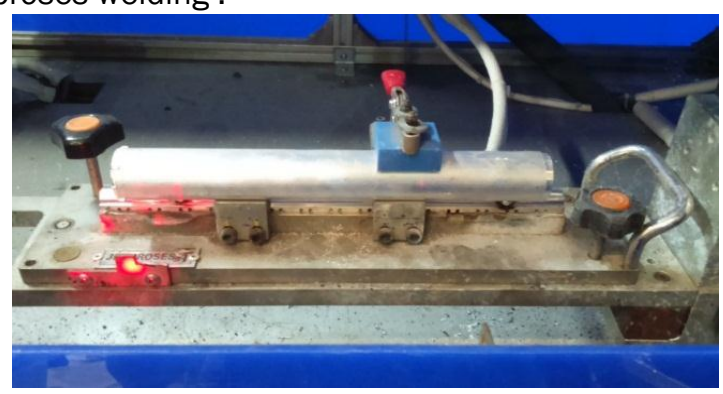

Gambar 8 Realisasi pembuatan jig unit welding modulator dengan tank header

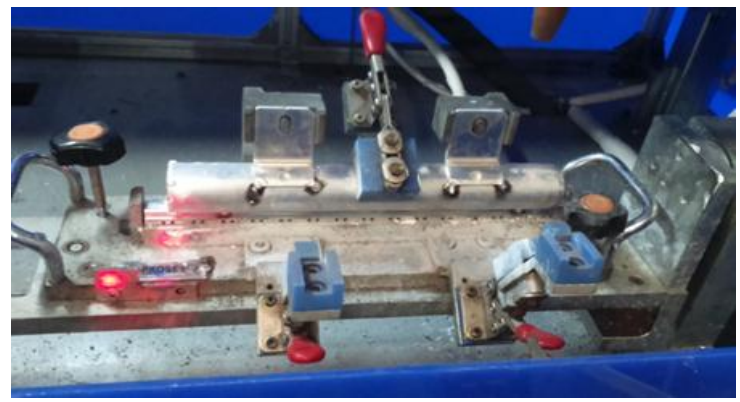

Gambar 9 Realisasi pembuatan jig welding modulator dengan al-bracket

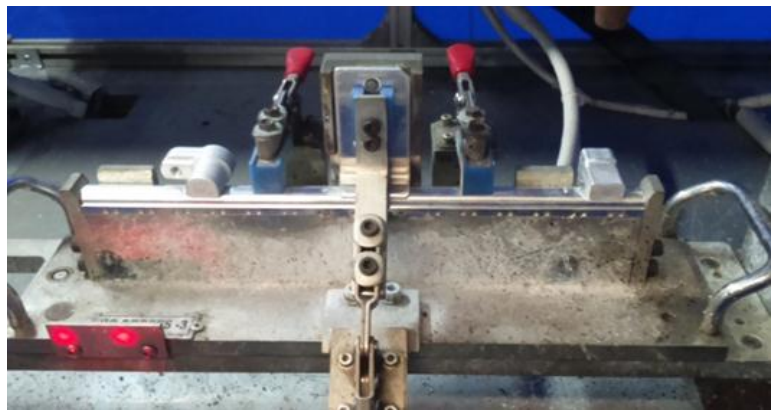

Gambar 10 Realisasi pembuatan jig welding tank header dengan al-bracket

Gambar di atas menunjukan realisasi pembuatan jig rotary table dan jig clamping untuk model XY. Jig clamping ini digunakan untuk menahan part agar tidak terlepas atau berubah posisi saat melakukan proses welding. 


\subsection{Pembuatan Sistem Kontrol}

Pembuatan kontrol pada jig rotary table ini meliputi perakitan sistem elektrik, kontrol motor servo, dan pembuatan program. Perakitan sistem elektrik berisi komponen aktual yang digunakan pada perangkat input, proses, dan output. Kontrol motor servo menjelaskan tentang pengkabelan pada driver motor servo, PLC, dan motor servo itu sendiri. Pembuatan program dilakukan sesuai flow chart yang telah dibuat pada penjelasan sebelumnya.

\subsection{Analisa Hasil}

Setelah dilakukan perancangan, pembuatan, dan pengujian, maka selanjutnya adalah melakukan analisa hasil yang diperoleh. Hasil dari pembuatan sistem rotary table pada mesin spot welding akan ditunjukan pada gambar di bawah ini.

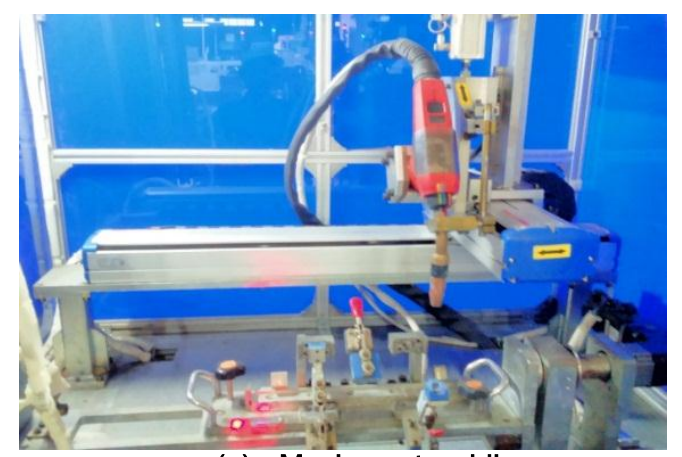

(a) Mesin spot welding

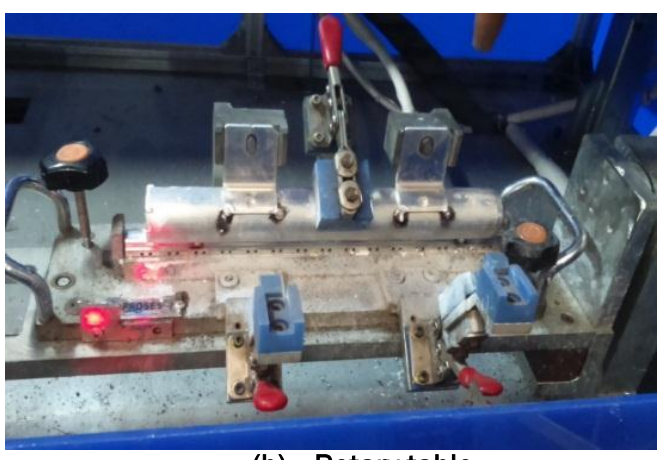

(b) Rotary table

Gambar 11 Sistem rotary table pada mesin spot welding

Gambar di atas merupakan realisasi pembuatan mesin spot welding dengan sistem rotary table. Spesifikasi sudut welding yang dibutuhkan untuk membuat condenser model $\mathrm{XY}$ dapat terpenuhi dan membuktikan bahwa dengan menggunakan sistem kontrol dengan landasan teori yang digunakan dalam pembuatan alat ini dapat menghasilkan alat sesuai dengan harapan. Hasil dari perhitungan pulse yang dibutuhkan motor servo untuk membentuk sudut $17^{\circ}$ dapat diaplikasikan pada motor servo. Berikut gambar hasil dari proses welding.
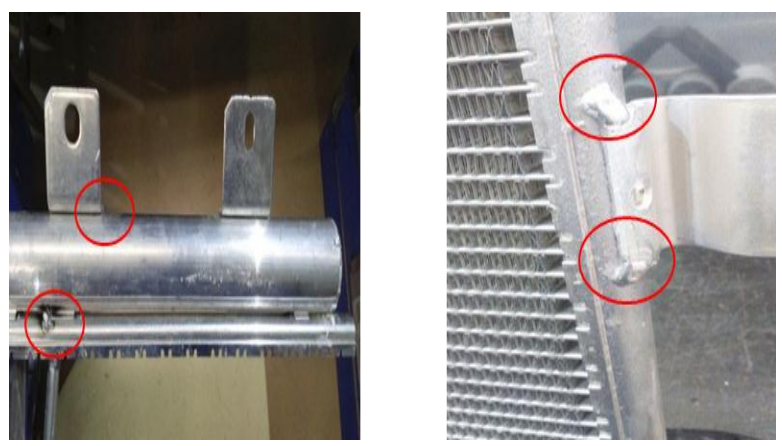

Gambar 12 Hasil welding al-braket menggunakan mesin spot welding

\section{Kesimpulan}

Pembuatan sistem rotary table menggunakan motor servo HG-KR43B yang dikontrol PLC FX3G$60 \mathrm{M}$ berhasil dilakukan dengan tambahan modul posisi FX2N-10PG dan driver motor MR-J4-40A.

\section{Daftar Pustaka}

[1] Bolton, W. (2009). Sistem Instrumentasi dan Sistem Kontrol. Jakarta: Erlangga.

[2] Ogata, K. (1985). Teknik Kontrol Otomatik 1st Ed. Jakarta: Erlangga.

[3] Pakpahan, S. (1998). Kontrol Otomatik. Jakarta: Erlangga.

[4] Setiawan, I. (2006). Programmable Logic Controller (PLC) dan Teknik Perancangan Sistem Kontrol. Yogyakarta: Erlangga.

[5] Stefano, J. (1996). Sistem Pengendalian dan Umpan Balik. Jakarta: Erlangga. 